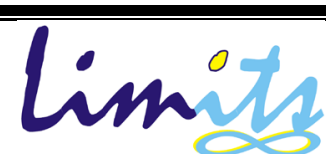

Limits: Journal of Mathematics and Its Applications

E-ISSN: 2579-8936

P-ISSN: 1829-605X

Vol. 18, No. 2, Nopember 2021, 109-117

DOI: http://dx.doi.org/10.12962/limits.v18i2.6479

\title{
Solusi Model Merokok Menggunakan Metode Perturbasi Homotopi
}

\author{
Mohamad Riyadi ${ }^{1}$, Daswa ${ }^{2}$, Mia Aditya Putri ${ }^{3}$ \\ ${ }^{1,2,3}$ Universitas Kuningan; Jln. Cut Nyak Dien No. 36A, Cijoho \\ ${ }^{1,3}$ Program Studi Pendidikan Matematika Universitas Kuningan Jawa Barat Indonesia \\ ${ }^{2}$ Program Studi Teknik Informatika Universitas Kuningan Jawa Barat Indonesia \\ e-mail:mohamad.riyadi@uniku.ac.id ${ }^{1}$,daswa@uniku.ac.id ${ }^{2}$,miadityap@gmail.com³
}

Diajukan: 28 Januari 2020, Diperbaiki: 3 Maret 2021, Diterima: 9 Juni 2021

\begin{abstract}
Abstrak
Artikel ini meninjau masalah dinamika perilaku merokok. Metode perturbasi homotopi diterapkan untuk menghitung solusi sistem persamaan differensial pada masalah tersebut. Hasil ini kemudian dibandingkan dengan hasil dari metode numerik. Hasil menunjukkan bahwa solusi metode perturbasi homotopi cenderung menghasilkan kecocokan yang baik terhadap solusi numerik pada beberapa selang waktu.

Kata Kunci: metode perturbasi homotopi, sistem persamaan differensial, model merokok

Abstract

This article considers the dynamics of smoking behavior. The homotopy perturbation method is applied to calculate the solution of the system of differential equations on the problem. Then, the results are compared with the results by numerical methods. The results show that the solutions of the homotopy perturbation method are in good agreement with the solutions of the numerical method at several time intervals.
\end{abstract}

Keywords: homotopy perturbation method, system of differential equation, smoking model

\section{Pendahuluan}

Dinamika perilaku merokok dapat dipelajari dengan pemodelan matematika. Pemodelan ini dapat membantu dalam menganalisis bagaimana penyebaran perilaku merokok. Model ini dapat menggunakan pendekatan pemodelan epidemi penyakit menular [1]. Melalui pendekatan ini, model mempertimbangkan kompartemen [2].

Pemodelan merokok yang menggambarkan dinamika trend pertumbuhan penggunaan narkoba dan tembakau diperkenalkan oleh [3]. Dia mengembangkan model dengan membagi populasi menjadi tiga subpopulasi yaitu perokok potensial, perokok dan perokok yang berhenti dengan mempertimbangkan beberapa faktor yang berpengaruh pada pertumbuhan penggunaan tembakau. [4] mengusulkan model matematika dinamika merokok dengan membagi populasi menjadi empat subpopulasi dengan mengenalkan dua kelas pada perokok yang berhenti, yaitu 
perokok yang berhenti sementara dan perokok yang berhenti permanen. Lebih lanjut mereka mengembangkan model menjadi enam subpopulasi dengan memperkenalkan perokok sedang, perokok berat dan kelas yang berhubungan dengan sakit akibat merokok. [5] mengembangkan model dengan model stokastik. Memodifikasi model Sharomi dengan memperkenalkan interaksi nonlinear antara perokok dan perokok yang berhenti sementara. [6] membangun model dengan meninjau model perokok kadang-kadang yang berhenti merokok. Kemudian [7] memodifikasi model tersebut dengan memperkenalkan suku interaksi akar kuadrat perokok potensial dan perokok kadang-kadang. Dan beberapa usaha dalam mencegah pertumbuhan perokok dengan melakukan kontrol dan kampanye sehat telah dikaji oleh beberapa peneliti [8], [9].

Model-model yang diuraikan di atas berbentuk sistem persamaan differensial tak linear. Solusi analitik terkadang sulit ditemukan. Solusi numerik kemudian digunakan untuk menghampiri solusi sistem persamaan differensial tersebut. Salah satu alternatif untuk mencari solusi numerik yaitu menggunakan metode perturbasi homotopi. Metode perturbasi homotopi diperkenalkan oleh [10].

Beberapa peneliti menggunakan metode ini untuk menentukan solusi sistem persamaan differensial. Di antara penerapan metode ini yaitu untuk masalah epidemik dan predator-prey [11], [12], solusi sistem stiff persamaan differensial biasa [13]-[15], untuk sistem persamaan differensial pecahan [16], untuk sistem persamaan differensial integro [17], [18], untuk sistem persamaan differensial parsial [19], untuk model SEIR [20], solusi persamaan Burger [21], untuk sistem reaksi difusi nonlinear pecahan [22] dan model difusi untuk masalah keuangan [23].

Penelitian ini membahas penerapan metode perturbasi homotopi pada sistem persamaan differensial pada model merokok. Hasil perhitungan metode perturbasi homotopi kemudian dibandingkan dengan hasil metode numerik.

\section{Metode Penelitian}

\subsection{Kontruksi Model}

Model merokok yang ditinjau pada penelitian ini yaitu model yang dikembangkan pada [3]. Total populasi $N(t)$ dibagi ke dalam tiga subpopulasi: perokok potensial, yaitu orang yang belum merokok tetapi mungkin menjadi perokok di masa depan; perokok; dan perokok yang berhenti permanen, dengan ukuran yang ditunjukkan oleh $P(t), S(t)$ dan $Q(t)$, berturut-turut. Beberapa asumsi ditetapkan di antaranya:

1) Nilai $c$ adalah rata-rata jumlah kontak per satuan waktu; $c P(t)$ adalah rata-rata jumlah kontak perokok potensial per satuan waktu. Individu perokok potensial berinteraksi dengan individu $P(t), S(t)$ dan $Q(t)$. 
2) Proporsi adanya perokok yang berinteraksi sehingga memungkinkan mempengaruhi perokok potensial adalah $S(t) / N(t)$. Maka, rata-rata jumlah kontak total adalah $c P(t) S(t) / N(t)$.

3) Nilai $\rho$ adalah probabilitas suatu pengaruh menghasilkan perokok dan $\varphi$ adalah proporsi individu menjadi perokok. Maka tingkat kejadian (incidence rate), yaitu perokok baru per satuan waktu, adalah $\beta P(t) S(t) / N(t)$, dengan $\beta=\varphi \rho c$, yaitu rata-rata tingkat pengaruh efektif.

4) Nilai $\lambda$ adalah tingkat pemulihan per perokok per satuan waktu dan $\delta$ adalah tingkat kambuh per individu yang sembuh per satuan waktu

5) Populasi diasumsikan konstan, yaitu setiap kematian seimbang dengan kelahiran populasi pada perokok potensial. Nilai $\mu$ adalah tingkat kematian konstan.

Model merokok sebagai berikut

$$
\begin{aligned}
& \frac{d P}{d t}=\mu N-\beta P \frac{S}{N}-\mu P, \\
& \frac{d S}{d t}=\beta P \frac{S}{N}-\lambda S+\delta Q-\mu S, \\
& \frac{d Q}{d t}=\lambda S-\delta Q-\mu Q
\end{aligned}
$$

dengan kondisi awal $P(0)=P_{0}, S(0)=S_{0}, Q(0)=Q_{0}$,

\subsection{Analisis Metode}

Berikut ini diberikan konsep dasar metode perturbasi homotopi berdasarkan pada [10]. Misalkan diberikan persamaan diferensial berikut:

$$
A[u(t)]=0
$$

dengan $A$ adalah operator diferensial umum, $t$ adalah variabel bebas, dan $u(t)$ adalah fungsi yang akan ditentukan. Didefinisikan operator linear $L$ yang memenuhi

$$
L[f]=0 \text { bila } f=0 .
$$

Didefinisikan suatu fungsi homotopi sebagai berikut:

$$
H[v(t, p), p]=(1-p) L\left[v(t, p)-u_{0}(t)\right]+p A[v(t, p)]=0
$$

dengan $u_{0}$ merupakan pendekatan awal dari penyelesaian Persamaan (2), dan $p$ merupakan parameter dimana $p \in[0,1]$. Berdasarkan Persamaan (3) maka pada saat $p=0$ memberikan persamaan:

$$
H[v(t, 0), 0]=L\left[v(t, 0)-u_{0}(t)\right]=0
$$

dan untuk $p=1$ memberikan persamaan:

$$
H[v(t, 1), 1]=A[v(t, 1)]=0 .
$$


Sehingga $v(t, 0)=u_{0}(t)$ merupakan penyelesaian dari persamaan $H[v(t, 0), 0]=0$ dan $v(t, 1)=u(t)$ merupakan penyelesaian dari $H[v(t, 1), 1]=0$. Asumsikan bahwa solusi dari Persaman (3) dapat ditulis sebagai deret pangkat dalam $p$

$$
v=v_{0}+p v_{1}+p^{2} v_{2}+p^{3} v_{3}+\cdots
$$

Tetapkan $p=1$ sehingga diperoleh solusi pendekatan dari Persamaan (2) adalah sebagai berikut:

$$
u=\lim _{p \rightarrow 1} v=v_{0}+v_{1}+v_{2}+v_{3}+\cdots .
$$

\section{Hasil dan Pembahasan}

Pada bagian ini, metode perturbasi homotopi diterapkan untuk menyelesaikan model merokok. Kemudian hasil tersebut dibandingkan dengan metode numerik untuk menilai keakuratan metode perturbasi homotopi. Transformasi variabel diterapkan untuk penyederhanaan model.

Misal $P^{*}=\frac{P}{N}, S^{*}=\frac{S}{N}$, dan $Q^{*}=\frac{Q}{N}$ menyatakan pecahan untuk populasi $P, S$, dan $Q$. Untuk kemudahan penulisan notasi, $P^{*}, S^{*}$, dan $Q^{*}$ ditulis $P, S$, dan $Q$. Persamaan (1) dapat ditulis sebagai

$$
\begin{aligned}
& \frac{d P}{d t}=\mu-\beta P S-\mu P, \\
& \frac{d S}{d t}=\beta P S-\lambda S+\delta Q-\mu S, \\
& \frac{d Q}{d t}=\lambda S-\delta Q-\mu Q
\end{aligned}
$$

dengan kondisi awal $P(0)=P_{0}, S(0)=S_{0}, Q(0)=Q_{0}$.

Berdasarkan pada metode perturbasi homotopi, yaitu penerapan Persamaan (3) pada (4), diperoleh persamaan

$$
\begin{aligned}
(1-p)\left(\frac{\mathrm{d}}{\mathrm{d} t} P(t)-\left(\frac{\mathrm{d}}{\mathrm{d} t} P_{0}(t)\right)\right)+p\left(\frac{\mathrm{d}}{\mathrm{d} t} P(t)-\mu+\beta P(t) S(t)+\mu P(t)\right) & =0 \\
(1-p)\left(\frac{\mathrm{d}}{\mathrm{d} t} S(t)-\left(\frac{\mathrm{d}}{\mathrm{d} t} S_{0}(t)\right)\right)+p\left(\frac{\mathrm{d}}{\mathrm{d} t} S(t)-\beta P(t) S(t)+(\mu+\lambda) S(t)-\delta Q(t)\right) & =0 \\
(1-p)\left(\frac{\mathrm{d}}{\mathrm{d} t} Q(t)-\left(\frac{\mathrm{d}}{\mathrm{d} t} Q_{0}(t)\right)\right)+p\left(\frac{\mathrm{d}}{\mathrm{d} t} Q(t)-\lambda S(t)+(\mu+\delta) Q(t)\right) & =0
\end{aligned}
$$

dengan $p \in[0,1]$ suatu parameter dan $P_{0}, S_{0}$, dan $Q_{0}$ adalah pendekatan awal dari penyelesaian. Misalkan penyelesaian dari Persamaan (5) dinyatakan dalam deret pangkat

$$
\begin{aligned}
& P=P_{0}(t)+p \cdot P_{1}(t)+p^{2} \cdot P_{2}(t)+p^{3} \cdot P_{3}(t)+p^{4} \cdot P_{4}(t) \\
& S=S_{0}(t)+p \cdot S_{1}(t)+p^{2} \cdot S_{2}(t)+p^{3} \cdot S_{3}(t)+p^{4} \cdot S_{4}(t) \\
& Q=Q_{0}(t)+p \cdot Q_{1}(t)+p^{2} \cdot Q_{2}(t)+p^{3} \cdot Q_{3}(t)+p^{4} \cdot Q_{4}(t)
\end{aligned}
$$


dengan kondisi awal $P(0)=P_{0}, S(0)=S_{0}, Q(0)=Q_{0}$. Jika Persamaan (6) beserta turunan-turunannya disubstitusikan ke Persamaan (5), maka koefisien $p^{1}$ memberikan

$$
\begin{array}{r}
\frac{\mathrm{d}}{\mathrm{d} t} P_{1}(t)+\frac{\mathrm{d}}{\mathrm{d} t} P_{0}(t)-\mu+\mu P_{0}(t)+\beta P_{0}(t) S_{0}(t)=0 \\
\frac{\mathrm{d}}{\mathrm{d} t} S_{1}(t)+\frac{\mathrm{d}}{\mathrm{d} t} S_{0}(t)+(\mu+\lambda) S_{0}(t)-\delta Q_{0}(t)-\beta P_{0}(t) S_{0}(t)=0 \\
\frac{\mathrm{d}}{\mathrm{d} t} Q_{1}(t)+\frac{\mathrm{d}}{\mathrm{d} t} Q_{0}(t)-\lambda S_{0}(t)+(\mu+\delta) Q_{0}(t)=0
\end{array}
$$

dengan kondisi awal $P_{1}(0)=0, S_{1}(0)=0, Q_{1}(0)=0$. Koefisien $p^{2}$ memberikan

$$
\begin{array}{r}
\frac{\mathrm{d}}{\mathrm{d} t} P_{2}(t)+\mu P_{1}(t)+\beta P_{0}(t) S_{1}(t)+\beta P_{1}(t) S_{0}(t)=0 \\
\frac{\mathrm{d}}{\mathrm{d} t} S_{2}(t)-\delta Q_{1}(t)+(\mu+\lambda) S_{1}(t)-\beta P_{0}(t) S_{1}(t)-\beta P_{1}(t) S_{0}(t)=0 \\
\frac{\mathrm{d}}{\mathrm{d} t} Q_{2}(t)+(\mu+\delta) Q_{1}(t)-\lambda S_{1}(t)=0
\end{array}
$$

dengan kondisi awal $P_{2}(0)=0, S_{2}(0)=0, Q_{2}(0)=0$. Koefisien $p^{3}$ memberikan

$$
\begin{array}{r}
\frac{\mathrm{d}}{\mathrm{d} t} P_{3}(t)+\mu P_{2}(t)+\beta P_{0}(t) S_{2}(t)+\beta P_{1}(t) S_{1}(t)+\beta P_{2}(t) S_{0}(t)=0 \\
\frac{\mathrm{d}}{\mathrm{d} t} S_{3}(t)-\delta Q_{2}(t)-\beta P_{0}(t) S_{2}(t)-\beta P_{1}(t) S_{1}(t)-\beta P_{2}(t) S_{0}(t)+(\mu+\lambda) S_{2}(t)=0 \\
\frac{\mathrm{d}}{\mathrm{d} t} Q_{3}(t)+(\mu+\delta) Q_{2}(t)-\lambda S_{2}(t)=0
\end{array}
$$

dengan kondisi awal $P_{3}(0)=0, S_{3}(0)=0, Q_{3}(0)=0$. Koefisien $p^{4}$ memberikan

$$
\begin{array}{r}
\frac{\mathrm{d}}{\mathrm{d} t} P_{4}(t)+\beta P_{0}(t) S_{3}(t)+\beta P_{1}(t) S_{2}(t)+\beta P_{2}(t) S_{1}(t)+\beta P_{3}(t) S_{0}(t)+\mu P_{3}(t)=0 \\
\frac{\mathrm{d}}{\mathrm{d} t} S_{4}(t)-\delta Q_{3}(t)+(\mu+\lambda) S_{3}(t) \\
-\beta P_{0}(t) S_{3}(t)-\beta P_{1}(t) S_{2}(t)-\beta P_{2}(t) S_{1}(t)-\beta P_{3}(t) S_{0}(t)=0 \\
\frac{\mathrm{d}}{\mathrm{d} t} Q_{4}(t)-\lambda S_{3}(t)+(\mu+\delta) Q_{3}(t)=0
\end{array}
$$

dengan kondisi awal $P_{4}(0)=0, S_{4}(0)=0, Q_{4}(0)=0$.

Kondisi awal dari Persamaan (4) adalah $P(0)=0.8, S(0)=0.2, Q(0)=0.01$ dan nilai parameter yang diambil dari [3] yaitu $\beta=0.625, \mu=0.10, \lambda=0.15, \delta=0.89$. Dengan menyelesaikan Persamaan (7) - (10) dengan kondisi awalnya, maka diperoleh penyelesaian masalah nilai awal (4) menggunakan metode perturbasi homotopi hingga orde keempat yaitu

$$
\begin{aligned}
& P(t)=0.8-0.08 t-0.005725 t^{2}-0.0004734583333 t^{3}+0.0004605472135 t^{4} \\
& S(t)=0.2+0.0589 t+0.011307 t^{2}-0.001919118333 t^{3}+0.0002032116157 t^{4} \\
& Q(t)=0.01+0.0201 t-0.005532 t^{2}+0.002390910000 t^{3}-0.0006637171625 t^{4}
\end{aligned}
$$


Hasil ini kemudian dibandingkan dengan solusi numeriknya. Perbandingan galat disajikan pada Tabel 1.

Tabel 1. Galat dan rata-rata galat antara solusi numerik dan solusi metode perturbasi homotopi untuk $P(t), S(t)$, dan $Q(t)$

\begin{tabular}{cccc}
\hline$t$ & $\left|P_{\text {num }}-P_{m p h}\right|$ & $\left|S_{\text {num }}-S_{m p h}\right|$ & $\left|Q_{n u m}-Q_{m p h}\right|$ \\
\hline 0 & 0 & 0 & 0 \\
0.1 & $2.99 \times 10^{-6}$ & $5.45 \times 10^{-6}$ & $2.44 \times 10^{-6}$ \\
0.2 & $6.20 \times 10^{-6}$ & $1.05 \times 10^{-5}$ & $4.30 \times 10^{-6}$ \\
0.3 & $9.50 \times 10^{-6}$ & $1.54 \times 10^{-5}$ & $5.89 \times 10^{-6}$ \\
0.4 & $1.27 \times 10^{-5}$ & $2.05 \times 10^{-5}$ & $7.76 \times 10^{-6}$ \\
0.5 & $1.53 \times 10^{-5}$ & $2.63 \times 10^{-5}$ & $1.09 \times 10^{-5}$ \\
0.6 & $1.68 \times 10^{-5}$ & $3.38 \times 10^{-5}$ & $1.68 \times 10^{-5}$ \\
0.7 & $1.65 \times 10^{-5}$ & $4.43 \times 10^{-5}$ & $2.76 \times 10^{-5}$ \\
0.8 & $1.31 \times 10^{-5}$ & $5.95 \times 10^{-5}$ & $4.62 \times 10^{-5}$ \\
0.9 & $5.29 \times 10^{-6}$ & $8.16 \times 10^{-5}$ & $7.61 \times 10^{-5}$ \\
1 & $8.79 \times 10^{-6}$ & $1.13 \times 10^{-4}$ & $1.22 \times 10^{-4}$ \\
\hline Rata-rata & $1.07 \times 10^{-5}$ & $4.11 \times 10^{-5}$ & $3.20 \times 10^{-5}$ \\
\hline
\end{tabular}

Berdasarkan Tabel 1, solusi dari metode perturbasi homotopi cenderung bersesuaian dengan solusi numeriknya. Rata-rata galat yang dihasilkan untuk populasi perokok potensial, perokok, dan perokok yang berhenti permanen sangat kecil pada $t \in[0,1]$. Hasil ini menunjukkan bahwa metode perturbasi homotopi dapat digunakan untuk menghampiri solusi dari model merokok. Adapun grafik solusi model merokok diberikan pada Gambar 1.
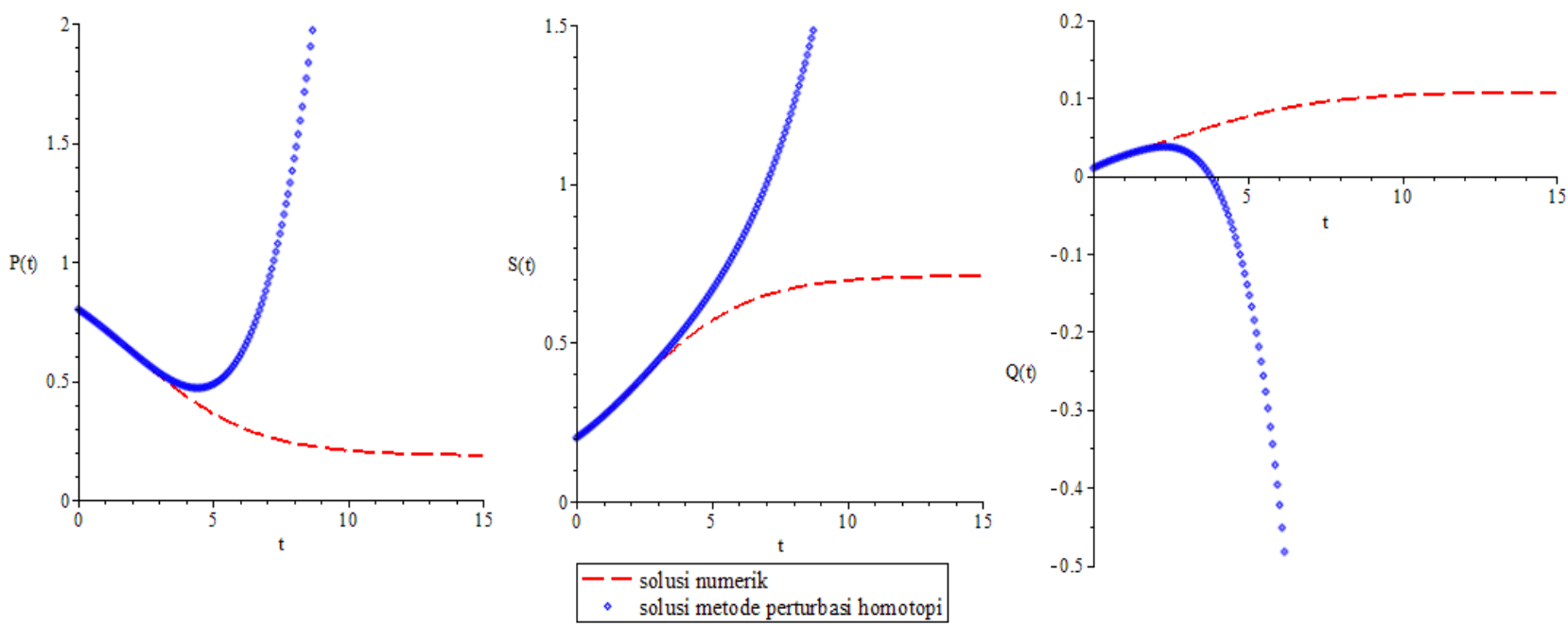

Gambar 1. Grafik solusi numerik dan solusi metode perturbasi homotopi untuk $P(t), S(t)$, dan $Q(t)$ 
Dari Gambar 1, grafik solusi numerik menunjukkan bahwa trayektori solusi model merokok untuk $P, S$, dan $Q$ menuju pada steady state untuk nilai awal yang diberikan. Nilai steady state masing-masing yaitu $(0.185,0.706,0.105)$. Untuk nilai parameter yang diberikan, populasi perokok potensial menurun kemudian menetap pada nilai steady state. Akan tetapi, populasi perokok dan populasi perokok yang berhenti permanen meningkat yang kemudian menetap pada nilai steady state. Sementara itu, grafik solusi metode perturbasi homotopi mengikuti grafik solusi numerik pada beberapa selang $t$. Beberapa selang $t$ yang menghasilkan galat yang kecil untuk $P$, $S$, dan $Q$ masing-masing adalah [0,3.8], [0, 3.5], dan [0, 2.3]. Bila $t$ melebihi selang tersebut, galat akan semakin besar, sehingga grafik solusi metode perturbasi homotopi akan menjauhi grafik solusi numeriknya.

\section{Simpulan}

Metode perturbasi homotopi dapat diterapkan dengan mudah pada model merokok yang dibangun. Solusi dihitung dengan metode ini hingga orde keempat. Kecocokan yang baik ditunjukkan pada hasil yang diperoleh antara metode perturbasi homotopi dengan hasil metode numerik untuk $t$ kecil. Penerapan metode perturbasi homotopi dapat dikaji lebih lanjut untuk orde yang lebih tinggi dan diterapkan untuk model dengan asumsi lain seperti adanya analisis terhadap mekanisme proses kambuh menjadi perokok.

\section{Ucapan Terima Kasih}

Ucapan terima kasih disampaikan kepada Universitas Kuningan melalui LPPM yang telah membiayai penelitian ini melalui skema Hibah Penelitian Internal Universitas Kuningan.

\section{Daftar Pustaka}

[1] D. C. Rowe, L. Chassin, C. C. Presson, D. Edwards, and S. J. Sherman, "An 'epidemic' model of adolescent cigarette smoking," Journal of applied social psychology, vol. 22, no. 4, pp. 261-285, 1992.

[2] F. Brauer, C. Castillo-Chavez, and C. Castillo-Chavez, Mathematical models in population biology and epidemiology, vol. 40. Springer, 2001.

[3] C. Castillo-Garsow, G. Jordan-Salivia, and A. R. Herrera, "Mathematical models for the dynamics of tobacco use, recovery," and relapse, 2000.

[4] O. Sharomi and A. B. Gumel, "Curtailing smoking dynamics: a mathematical modeling approach," Applied Mathematics and Computation, vol. 195, no. 2, pp. 475-499, 2008. 
[5] A. Lahrouz, L. Omari, D. Kiouach, and A. Belmaâti, "Deterministic and stochastic stability of a mathematical model of smoking," Statistics \& Probability Letters, vol. 81, no. 8, pp. 1276-1284, 2011.

[6] G. Zaman, "Qualitative behavior of giving up smoking models," Bulletin of the Malaysian Mathematical Sciences Society, vol. 34, no. 2, pp. 403-415, 2011.

[7] A. Zeb, G. Zaman, and S. Momani, "Square-root dynamics of a giving up smoking model," Applied Mathematical Modelling, vol. 37, no. 7, pp. 5326-5334, 2013.

[8] L. Pang, Z. Zhao, S. Liu, and X. Zhang, "A mathematical model approach for tobacco control in China," Applied Mathematics and Computation, vol. 259, pp. 497-509, 2015.

[9] A. Yadav, P. K. Srivastava, and A. Kumar, "Mathematical model for smoking: Effect of determination and education," International Journal of Biomathematics, vol. 8, no. 01, p. $1550001,2015$.

[10] J.-H. He, “A coupling method of a homotopy technique and a perturbation technique for nonlinear problems," International Journal of Non-Linear Mechanics, vol. 35, no. 1, pp. 37-43, 2000.

[11] M. Rafei, H. Daniali, D. D. Ganji, and H. Pashaei, "Solution of the prey and predator problem by homotopy perturbation method," Applied Mathematics and Computation, vol. 188, no. 2, pp. 1419-1425, 2007.

[12] M. Rafei, D. D. Ganji, and H. Daniali, "Solution of the epidemic model by homotopy perturbation method," Applied Mathematics and Computation, vol. 187, no. 2, pp. 10561062, 2007.

[13] H. Aminikhah, "The combined Laplace transform and new homotopy perturbation methods for stiff systems of ODEs," Applied Mathematical Modelling, vol. 36, no. 8, pp. 3638-3644, 2012.

[14] H. Aminikhah and M. Hemmatnezhad, "An effective modification of the homotopy perturbation method for stiff systems of ordinary differential equations," Applied Mathematics Letters, vol. 24, no. 9, pp. 1502-1508, 2011.

[15] J. Biazar, M. A. Asadi, and F. Salehi, "Rational Homotopy Perturbation Method for solving stiff systems of ordinary differential equations," Applied Mathematical Modelling, vol. 39, no. 3, pp. 1291-1299, 2015.

[16] O. Abdulaziz, I. Hashim, and S. Momani, "Solving systems of fractional differential equations by homotopy-perturbation method," Physics Letters A, vol. 372, no. 4, pp. 451459, 2008. 
[17] J. Biazar, H. Ghazvini, and M. Eslami, "He's homotopy perturbation method for systems of integro-differential equations," Chaos, Solitons \& Fractals, vol. 39, no. 3, pp. 1253-1258, 2009.

[18] P. Roul and P. Meyer, "Numerical solutions of systems of nonlinear integro-differential equations by Homotopy-perturbation method," Applied Mathematical Modelling, vol. 35, no. 9, pp. 4234-4242, 2011.

[19] J. Biazar and M. Eslami, "A new homotopy perturbation method for solving systems of partial differential equations," Computers \& Mathematics with Applications, vol. 62, no. 1, pp. 225-234, 2011.

[20] Jaharuddin, "Homotopy perturbation method for a SEIR model with varying total population size," Far East Journal of Mathematical Sciences, vol. 2, 2014.

[21] M. Suleman, Q. Wu, and G. Abbas, "Approximate analytic solution of $(2+1)$ dimensional coupled differential Burger's equation using Elzaki Homotopy Perturbation Method," Alexandria Engineering Journal, vol. 55, no. 2, pp. 1817-1826, 2016.

[22] M. H. Tiwana, K. Maqbool, and A. B. Mann, "Homotopy perturbation Laplace transform solution of fractional non-linear reaction diffusion system of Lotka-Volterra type differential equation," Engineering Science and Technology, an International Journal, vol. 20, no. 2, pp. 672-678, 2017.

[23] C. R. B. Moutsinga, E. Pindza, and E. Maré, "Homotopy perturbation transform method for pricing under pure diffusion models with affine coefficients," Journal of King Saud University - Science, vol. 30, no. 1, pp. 1-13, 2018. 